Acta vet. scand. $1970,11,186-196$.

From the Animal Hospital at Strömsholm, Sweden.

\title{
EPIDURAL ANALGESIA IN DOGS WITH SPECIAL REFERENCE TO THE INTRAARTERIAL BLOOD PRESSURE
}

By

Folke Persson

Since it was introduced in 1901 epidural analgesia has been used to a large extent in veterinary medicine for orthopedic, abdominal and perineal surgery. As epidural blockade has a very complicated mechanism owing to several variables, it is understandable that during certain periods the technique has been considered as more or less loaded with the risk of complications. This has not only been caused by lack of knowledge of the effect of the analgesics but also by the fact that experiences from human medicine have been transferred to veterinary medicine without sufficient critical investigation. An analgesic with an ideal effect on small animals with little size and weight is not necessarily ideal for large animals and vice versa.

The effect of an analgesic is best studied by measurements of its capacity to block sensory and motor responses. The complicated mechanism of the epidural blockade can be appreciated by the fact that in addition to other factors, the blockade does not follow the ordinary laws of diffusion whereby intensity and quality of analgesia mainly depend on the concentration of the analgesic. According to Rohmann et al. (1959) the diffusing capacity of a local anaesthetic is not in direct proportion to its concentration. The earlier idea that the volume of the analgesic solution determines the segmental extent of the analgesia has also been shown to be incorrect. Bromage (1962) has shown that these functions are determined by the mass of the injected drug, i.e. the product of volume and concentration. Another characteristic of a local analgesic is that its uptake by nerves is timedependent. Thus, a prolonged or repeated injection of a local 
analgesic leads to a greater accumulation of drug per unit mass of nerve than a single, rapid injection (Bromage et al. 1964). Finally, it has long been known that the uptake by the nerve tissue of a local analgesic is favoured by a reduced regional blood flow. In this manner the prolonged action of a local analgesic by the addition of a vascoconstrictor, such as adrenaline, is explained. Rülcker (1964) showed by comparative investigations in epidural blockade in cows that the use of a $2 \%$ solution of lidocaine ${ }^{\star}$ ) in a certain dosage gave longer duration to motor blockade if an addition of adrenaline was made. The duration of the sensory blockade, however, showed no statistically significant deviation.

High spinal or epidural blockade in the human produces a decrease in blood pressure owing to the effect of the analgesic on the sympathetic nerves. From this it had been thought that the same alteration should occur in epidural blockade in animals. This is probably true, if large doses are administered rapidly in a single injection; this was the finding in pigs reported by Bollwahn (1963), who made blood pressure determinations using an indirect method according to Riva-Rocci. Müller et al. (1964) using the measurement method of Brecht and Boucke in dogs, concluded that a blood pressure fall contingent on epidural blockade did not exist. This conclusion, as in other reports, was based on indirect measuring methods. These authors also indicated that blood pressure measurements connected with epidural analgesia had been made only occasionally (Frey 1951), and only with indirect methods.

In Sweden, traditionally, a $2 \%$ solution of mepivacaine chloride $^{\star \star}$ ) or lidocaine chloride with addition of adrenaline in a concentration of $1: 100,000$ and $1: 80,000$ respectively for epidural analgesia in dogs has been used most often. Even without the addition of adrenaline the first mentioned solution is considered to have a longer effect than other analgesics (Pharmaconomia Veterinaria Svecica 1967), so it seemed desirable to determine the relative efficacy of different solutions of mepivacaine chloride with varied concentrations of adrenaline. The purpose of the present investigation was to find out which type of analgesic, considering both its concentration and the addition of adrenaline,

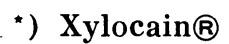

**) Carbocain $®$ 
is most suitable for epidural analgesia in dogs. For these studies the epidural blockades were carried out in a manner used routinely in the clinic to perform orthopedic, abdominal and perineal operations.

\section{MATERIALS AND METHODS}

Thirty-five dogs, which were brought to the Animal Hospital for orthopedic, abdominal or perineal operations, were used for these investigations. For epidural blockade the following three solutions were used:

Solution $A=1 \%$ mepivacaine chloride with adrenaline 1:200,000 Solution B $=2 \% \quad$, $\quad$ " $\quad$, $1: 100,000$ Solution $\mathrm{C}=2 \% \quad$ " $\quad$ " $\quad$ " $\quad 1: 200,000$

The investigation was performed as a double blind test with randomization of solutions, which guaranteed an equal distribution of the three solutions between the dogs. The experiments were performed according to the following schedule:

1. The sex, age and length of the dog were recorded.

2. Electrocardiogram (EGG) was performed.

3. A teflon catheter was inserted into the femoral artery. This manipulation was made without premedication and without regional analgesia.

4. Monitoring of the blood pressure.

5. Subcutaneous injection of ephedrine chloride in a dosage of $0.5-1.0 \mathrm{mg} / \mathrm{kg}$ body weight.

6. Blood pressure monitored.

7. Performance of epidural analgesia with continuous blood pressure monitoring.

8. ECG performed.

9. Performance of the operation under continuous blood pressure monitoring, readings being taken every ten min.

10. ECG performed.

The following is a description of the materials and methods employed in the experimental schedule above.

1. A summary of the data is presented in Table 1. The total number of breeds was 15. Group $\mathrm{C}$ consisted of dogs a little older and larger than the other groups. These differences, however, lacked clinical significance.

2. The results of the ECG tracings will be published elsewhere.

3. To insert the teflon catheter in the femoral artery a thin needle was used. Through this a nylon line (monofilament fishing-line) was inserted. After the needle was removed the 
Table 1. The data of the patient material.

\begin{tabular}{cccrrrrr}
\hline $\begin{array}{c}\text { Analgesic } \\
\text { solution }\end{array}$ & $\begin{array}{l}\text { Number Number Males Females } \\
\text { of dogs of breeds }\end{array}$ & $\begin{array}{c}\text { Age in } \\
\text { years } \\
\overline{\mathbf{x}} \pm \text { s.e.m. }\end{array}$ & $\begin{array}{c}\text { Weigth } \\
\text { in kg } \\
\pm \text { s.e.m. }\end{array}$ & $\begin{array}{c}\text { Length } \\
\text { in cm } \\
\overline{\mathbf{x}} \pm \text { s.e.m. }\end{array}$ \\
\hline A & 12 & 8 & 4 & 8 & $4.4 \pm 0.9$ & $16 \pm 2.2$ & $62 \pm 2.4$ \\
B & 12 & 9 & 2 & 10 & $4.0 \pm 0.8$ & $18 \pm 4.0$ & $61 \pm 5.6$ \\
C & 11 & 6 & 5 & 6 & $7.0 \pm 0.7$ & $25 \pm 3.1$ & $72 \pm 3.3$ \\
\hline
\end{tabular}

$\overline{\mathbf{x}}=$ mean.

s.e.m. = standard error of the mean.

teflon catheter was put on the nylon and could, by this means, be inserted into the femoral artery without incising the skin and without risk of subsequent hemorrhage.

4. Blood pressure recordings were performed in 16 dogs by connecting the teflon catheter to a mercury manometer. In this way the mean arterial pressure was recorded. The blood pressure recording was observed continuously through the whole experiment. However, as an electro-manometer or other suitable instrument for continuous registration was unavailable, a reading was made every ten min.

5. Premedication with ephedrine was made in order to duplicate the treatment usually employed at the clinic.

6. As point 4 .

7. The epidural blockade was performed by inserting a needle in the lumbosacral intervertebral space, the dog in standing position. Analgesic solution was introduced at a dosage of $0.5 \mathrm{ml}$ every $30 \mathrm{sec}$. and was continued until the moment, when disappearance of the toe-reflexes was registered. Clinical experience indicates that when this reflex disappears, there is surgical analgesia with a segmental extent up to $\mathrm{T} 5$, i.e. a midthoracic block sufficient for abdominal surgery (Klide \& Soma 1968). As a measure of the sensory blockade the disappearance of the anal sphincter reflex was chosen for study. The disappearance of this reflex constitutes the first objective sign of the analgesic effect. The duration of time necessary for this disappearance is referred to in this study as "the latency of initial onset". Attempts to measure the "latency of complete spread" or the "extent of spread" with the pin prick method were unsatisfactory so this method was discarded. With the "toe-reflex" method, however, 
it was possible to estimate that, as a rule, complete sensory blockade set in only shortly before or at the same time as did the complete motor blockade. The criterion of the latter was complete inability to move legs or feet. It should be mentioned that a beginning motor blockade (inability to raise the tail) appeared at about the same time as the initial onset of the sensory blockade.

In a similar manner the duration of the sensory blockade was only slightly shorter than the duration of the motor blockade. To measure the latter it was necessary to note the duration from its onset until the moment when the dog was able to rise.

8. As point 2.

9. The mean duration of time for the performance of the operations was $33 \mathrm{~min}$. for group A, $39 \mathrm{~min}$. for group B and 38 min. for group C.

10. As point 2.

\section{RESULTS}

The results of the epidural blockade caused by the three various solutions are presented in Table 2.

Table 2. Latency of sensory onset and complete motor blockade in epidural blockade in dogs with various analgesic solutions of mepivacaine chloride.

\begin{tabular}{cccccc}
\hline $\begin{array}{c}\text { Analgesic } \\
\text { solution }\end{array}$ & \multicolumn{2}{c}{$\begin{array}{c}\text { Latency of sensory onset } \\
\text { (in min.) }\end{array}$} & & \multicolumn{2}{c}{$\begin{array}{c}\text { Time for complete spread } \\
\text { of motor blockade in min. }\end{array}$} \\
\cline { 2 - 3 } & $\overline{\mathrm{x}}$ & s.e.m. & & $\overline{\mathrm{x}}$ & s.e.m. \\
\hline A & 2.8 & 0.6 & & 6.7 & 0.7 \\
B & 1.8 & 0.2 & & 5.1 & 0.6 \\
C & 2.4 & 0.5 & & 5.6 & 0.8 \\
\hline
\end{tabular}

$\overline{\mathbf{x}}=$ mean.

s.e.m. = standard error of the mean.

It should be observed that the time needed for complete sensory blockade, though not measured exactly, more or less coincided with the time needed for complete motor blockade. In the comparison of the values given in Table 2, Student's t-test was used for determining the degree of significance. No significant difference in the latency of sensory onset time or in the time for 
the complete spread of motor blockade was found between the three solutions $(P>0.05)$. F-tests on the variances of the onset time show that solution $B$ probably differs from solution $\mathrm{C}(\mathbf{0 . 0 5}$ $>\mathrm{P}>0.01)$ and significantly from solution $\mathrm{A}(0.01>\mathrm{P}>0.001)$, i.e. that solution $B$ gave a more uniform onset time than did solutions $\mathrm{A}$ and $\mathrm{C}$.

The duration of the motor blockade is presented in Table 3.

T able 3. Duration of the motor blockade in min. in epidural blockade with three various solutions of mepivacaine chloride.

\begin{tabular}{ccc}
\hline $\begin{array}{c}\text { Analgesic } \\
\text { solution }\end{array}$ & $\overline{\mathbf{x}}$ & s.e.m. \\
\hline A & 149 & 13 \\
B & 180 & 17 \\
C & 159 & 12 \\
\hline
\end{tabular}

$\overline{\mathbf{x}}=$ mean.

s.e.m. $=$ standard error of the mean.

Analysis of variance shows that the apparent difference in duration of the motor blockade is without significance $(P>0.05)$.

The results of the blood pressure measurements are presented in Fig. 1. From this it is seen that the mean blood pressure did

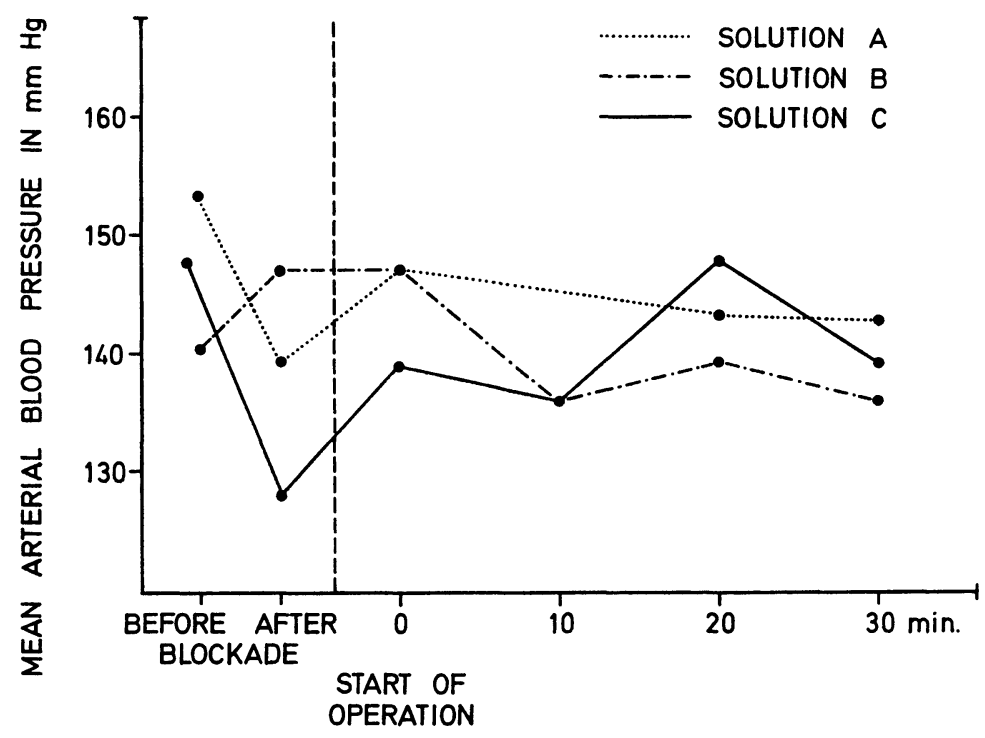

Figure 1. Mean values of the mean arterial blood pressure before and after operation. 
not differ significantly between the various groups. Furthermore, marked changes of blood pressure during analgesia or during the operations were not recorded. As continuous blood pressure observations were made, special attention was paid to the blood pressure during the performance of the epidural blockade as well as at the moment when the operation was started. No change of blood pressure was recorded at these times.

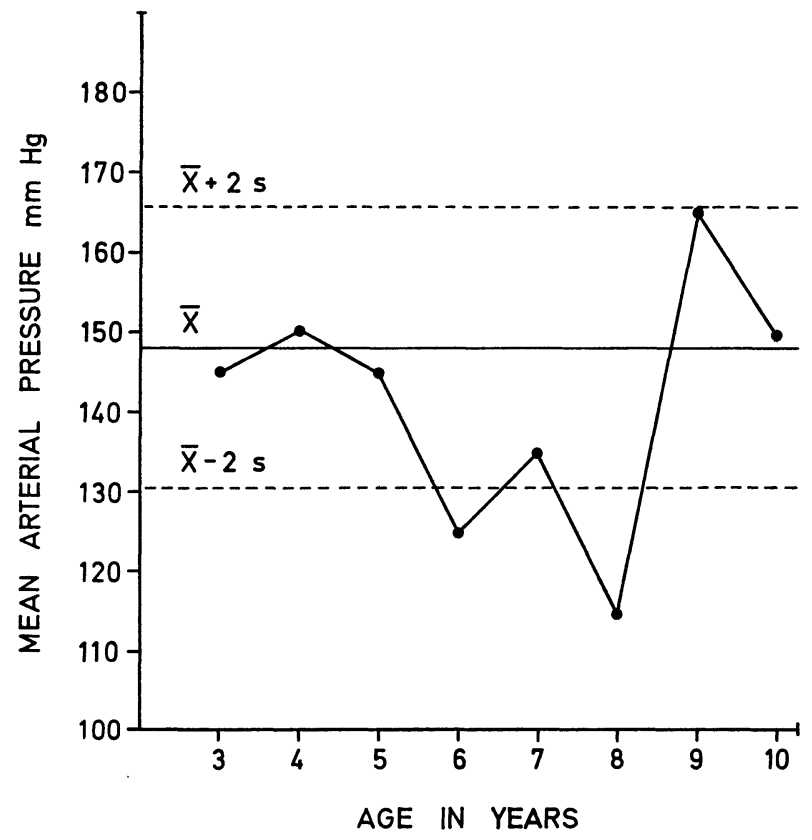

Figure 2. Mean values of the initial mean arterial pressure for dogs of different ages. The lines of short dashes indicate the mean values with the ranges of 2 standard deviations for normal dogs.

As dogs of all ages between 3 and 10 years were used it is of interest to present the differences of the initial pressure between dogs of various ages. From Fig. 2 it will be seen that the mean values of the blood pressure deviate significantly from the blood pressure of normal dogs only concerning dogs of the ages of 6 and 8 years. As there was only one dog of each of these ages the deviation is of little or no interest. Persson et al. (1961) reported the mean values for the mean arterial pressure of normal dogs as being $148 \mathrm{~mm} \mathrm{Hg} \pm 8.7 \mathrm{~s}$. It is also seen that a notable difference in the blood pressure between dogs of various ages does not exist. 


\section{DISCUSSION}

The present investigations were made on routine canine clinical cases employing a technique for epidural blockade generally used at the clinic. For this reason the dosage of the analgesics was not determined beforehand but was based rather on what was necessary to give an analgesia sufficient for the surgical procedures. It would have been interesting to compare the dosages arrived at in this manner with the dosages reported in the literature for equivalent surgical analgesia (Otsuka \& Nagakura 1966; Strande 1968; Klide \& Soma 1968). Such a comparison can be made only if the patients are divided in groups, for instance, as to size or as to weight. As the present study concerns three various solutions of analgesics further division into groups on the basis of size or weight would make the groups too small for statistical evaluation. For this reason a special presentation of the size of the dosages has not been done. From Table 2, however, it is possible in an indirect manner to find out the mean dosage of each analgesic, as the time for complete spread of motor blockade, given in min., is the same as the dosage, given in $\mathrm{ml}$. Even if the differences between the dosages for the three various solutions are not significant, the tendency agrees well with what should be expected, if we agree with the opinion of Bromage (1962), that the intensity and quality of the analgesia is governed by the mass of drug injected, i.e. the product of volume and concentration. In the investigations made by Bromage et al. (1964) it was shown that when lidocaine with added adrenaline was used for epidural blockade in human beings a longer latency of onset time was recorded for a $1 \%$ solution than for a $2 \%$ solution. When the latter was used a shorter time for complete spread of the analgesia was also recorded. These times were shortened further when a $3 \%$ solution was used, but were again prolonged for a $4 \%$ solution and a $5 \%$ solution. It is interesting that the results were just opposite if a plain lidocaine solution was used. In the present investigations (Table 2 ), where only $1 \%$ and $2 \%$ solutions with added adrenaline were used, it was shown that concerning these two solutions, there is conformity with the results of Bromage et al., i.e. that a $1 \%$ solution gave a longer latency onset time and also a longer time for complete sensory and motor blockade than did the $2 \%$ solution. The $2 \%$ solution with a higher concentration 
of adrenaline gave, as expected, a further shortened latency onset time and a still more shortened time for complete blockade.

Concerning the duration of the blockade, the duration of the sensory blockade was shorter than or equivalent to the duration of the motor blockade (Table 3). Even if the differences are not significant, it can be seen that the $2 \%$ solution with the highest concentration of adrenaline $(1: 100,000)$ shows the longest duration of the motor blockade. In large animals, for instance in cows, it is a disadvantage to prolong the duration of the motor blockade by using analgesics with added adrenaline (Rülcker 1964), if only a relatively short analgesia is needed. Of the three tested analgesics none showed a significant difference in the duration of the epidural blockade in dogs; therefore, considering the above, it does not appear to matter which one of the three solutions is chosen. Essential differences in sensory or motor onset time not being found, other factors must determine the choice of analgesics, as for instance the risk of complications such as blood pressure decreases, too high blood concentrations, etc.

The experiments showed that no blood pressure changes were caused by the epidural blockade or by the surgical procedures. This is an important observation which means that with the technique and dosage used, epidural blockade with mepivacaine is very safe and free of complications.

In the report of Klide \& Soma the following statement is made: "An advantageous property of lidocaine which has not been found in other local anesthetics is that of producing considerable sedation after absorption from the epidural space". In the present experiments no investigations were made regarding blood concentrations of the various solutions used for the blockade. Therefore it is of interest to mention that from earlier investigations the present author, together with others (Jorfeldt et al. 1964), have reported that even a low blood concentration of mepivacaine in dogs causes some general analgesic effect, which can be noticed not only clinically but also by means of electroencephalography.

Thus, our results are not in accordance with the opinion of Klide \& Soma. It is also felt that a high blood concentration of the analgesic should be avoided to minimize toxic effects. It appears certain that use of a higher concentration of the analgesic also causes higher blood levels. 
As a result of the present and earlier investigations where it is shown, that no significant differences exist between the three analgesic solutions, it can be recommended that when choosing between these solutions for epidural blockade in dogs the $1 \%$ solution with adrenaline 1:200,000 (solution A) should be preferred, followed by the $2 \%$ solution with adrenaline 1:200,000 (solution $\mathrm{C}$ ) and the $2 \%$ solution with adrenaline $(1: 100,000$ (solution B).

\section{ACKNOWLEDGMENTS}

This investigation was carried out with support from AB Bofors, Nobel-Pharma, Mölndal, Sweden.

Dr. Harry Mussman, the University of Nebraska, USA, who corrected my English, is also gratefully acknowledged.

\section{REFERENCES}

Bollwahn, W.: Experimentelle und klinische Untersuchungen zur Rückenmarksanaesthesie beim Schwein. (Experimental and clinical studies on spinal anaesthesia in the pig). Tierärztl. Umsch. 1963, 18, 271-279.

Bromage, P. R.: Spread of analgesic solutions in the epidural space and their site of action: A statistical study. Brit. J. Anaesth. 1962, 34, 161-178.

Bromage, P. R., M. F. Burfoot, D. E. Crowell \& R. T. Pettigrew: Quality of epidural blockade I: Influence of physical factors. Brit. J. Anaesth. 1964, 36, 342-352.

Frey, $H$. H.: Uber die lumbosacrale Epiduralanaesthesie beim Hund. (On lumbosacral epidural anaesthesia in the dog). Thesis. Hannover 1951.

Jorfeldt, L., B. Löfström, B. Pernow, F. Persson, J. Wahren \& B. Widman: The i.v. toxicity of LAC-43 in dog and man, evaluated by physiological methods. Report to AB Bofors, Nobel-Pharma 1964.

Klide, A. M. \& L. R. Soma: Epidural analgesia in the dog and cat. J. Amer. vet. med. Ass. 1968, 153, 165-173.

Müller, L. F., O. Dienemann, \& H. Müller: Der Einfluss der lumbosacralen Extradural-Anaesthesie auf den Blutdruck des Hundes. (The influence of lumbosacral extradural anaesthesia on blood pressure in the dog). Dtsch. tierärztl. Wschr. 1964, 71, 664-667.

Otsuka, H. \& Y. Nagakura: Epidural anaesthesia in the dog. Jap. vet. med. Ass. 1966, 19, 522-526.

Persson, F., S. Persson \& A. Asheim: Blood-pressure in dogs with renal cortical hypoplasia. Acta vet. scand. 1961, 2, 129-136.

Pharmaconomia Veterinaria Svecica, Sveriges Veterinärförbund, Stockholm 1967, p. 138.

Rohmann, C., T. Eckert \& G. Heil: Über einen Zusammenhang von Molekül-Assoziation und Wirkung bei Oberflächenanästhetika. 
(The relationship between molecular association and effect in surface anaesthesia). Arch. Pharm. (Weinheim) 1959, 29, 255260.

Rülcker, C.: Xylocain med och utan adrenalintillsats vid epiduralanestesi hos nötkreatur. (Xylocain with and without adrenaline in epidural anaesthesia in cattle). Svensk Vet.-Tidn. 1964, 16, $301-302$.

Strande, A.: Epidural anaesthesia in young pigs, dosage in relation to the length of the vertebral column. Acta vet. scand. 1968, 9, $41-49$.

\section{SUMMARY}

In order to investigate whether epidural analgesia in dogs employing mepivacaine chloride gives rise to complications, mainly changes in blood pressure, such analgesia was carried out in 35 dogs brought to the clinic for orthopedic, abdominal or perineal operations. Intra-arterial blood pressure measurements were made in 16 dogs. Three different solutions of mepivacaine chloride were used: $1 \%$ solution with adrenaline $1: 200,000 ; 2 \%$ solution with adrenaline $1: 100,000$ and $2 \%$ solution with adrenaline 1:200,000. The various solutions showed no significant difference in analgesic effect. Nor was any blood pressure change found during the epidural blockade. As a solution with a higher concentration causes a higher blood level of the analgesic and also greater toxic effects it is recommended that first preference be given to use of a $1 \%$ solution with adrenaline $1: 200,000$; second choice is a $2 \%$ solution with adrenaline $1: 200,000$ and third choice the $2 \%$ solution with adrenaline $1: 100,000$.

\section{SAMMANFATTNING \\ Epiduralblockad hos hundar med speciell hänsyn till det intra- arteriella blodtrycket.}

För att undersöka huruvida epiduralblockad hos hundar med användande av mepivacain (carbocain $®$ ) medför komplikationsrisker främst med avseende på förändringar till blodtrycket utfördes sådan. blockad på 35 hundar, som blev föremål för ortopediska, abdominella eller perineala operationer. 16 hundar blev föremål för blodtrycksmätningar enligt en direkt metod. Tre olika mepivacainlösningar användes: $1 \%$-ig lösning med adrenalintillsats i koncentrationen 1:200.000, $2 \%$-ig lösning med adrenalin 1:100.000 och $2 \%$-ig lösning med adrenalin 1:200.000. De olika lösningarnas analgesieffekt visade ingen signifikant skillnad. Ej heller framkom några blodtrycksförändringar under epiduralblockaden. Med tanke på att en mera högkoncentrerad lösning ger en större blodkoncentration och därmed större toxisk effekt rekommenderas att av de tre lösningarna i första hand använda $1 \%$-ig lösning med adrenalin 1:200.000, i andre hand $2 \%$-ig lösning med adrenalin 1:200.000 och i tredje hand $2 \%$-ig lösning med adrenalin $1: 100.000$.

(Received September 11, 1969). 